\title{
Categorías espacio-temporales escolares y andinas: un estudio en escuelas del noroeste argentino
}

\author{
ANQUÍN, Ana de ${ }^{1}$ \\ GUAYMÁS, Álvaro
}

\section{RESUMEN}

El artículo aborda las categorías de tiempo/espacio, en su dimensión estructurante, para intentar su desnaturalización, es decir para pensar sobre ellas y aceptar que son construcciones histórico-culturales. Por ello se insinúa una comparación entre las categorías de la modernidad occidental con los de la cultura andina, siguiendo los lineamientos de la hermenéutica diatópica tal como la enuncia Josef Esterman. Además se toman los aportes del giro decolonial que pone en duda la abstracción pura y la contrapone al pensamiento enraizado en la Abya Yala profunda (América para los occidentales), sin pretensiones de universalidad para comprender que sucede en las escuelas de lugares inhóspitos del noroeste de Argentina, en la frontera con Chile y Bolivia a partir de aprendizajes realizados a través de proyectos de investigación, en los cuales participaron miembros de las comunidades y de las escuelas, con la intención de analizar problemas y apuntalar las prácticas pedagógicas interculturales.

Tiempo/Espacio. Cultura Andina. Escuela. Pedagogía Intercultural. Salta.

\section{Categorias Espaço-Tempo na Escola e Andinas: um Estudo das Escolas do Nordeste da Argentina}

\section{RESUMO}

O artigo trata das categorias de tempo/espaço, em sua dimensão estruturante, para tentar sua desnaturação, ou seja, pensar sobre elas e aceitar que são construções histórico-culturais. Portanto, sugere-se uma comparação entre as categorias da modernidade ocidental e as da cultura andina, seguindo as diretrizes da hermenêutica diatópica, como a afirmação de Josef Esterman. Além disso, são tomadas as contribuições da virada decolonial que põem em

\footnotetext{
${ }^{1}$ Investigadora y fundadora del Centro de Investigaciones Sociales y Educativas del Norte argentino (Cisen) de la Universidad Nacional de Salta. Dirigió programas de investigación y extensión universitaria en las regiones Andinas (culturas coya y tastil) como en el Chaco (culturas chané y guaraní). Además es evaluadora y formadora en proyectos interculturales. Email: adeanquin@gmail.com. ORCID: https://orcid.org/0000-0002-7715-9998.

2 Coordinó el Profesorado de Educación Intercultural Bilingue en el IES № 6049. Actualmente es Editor Técnico de la Revista del Cisen Tramas/Maepova en la Universidad Nacional de Salta (UNSa), es miembro del Programa ESIAL "Educación Superior y Pueblos Indígenas y Afrodescendientes en América Latina" y participa de la Cátedra UNESCO "Educación Superior y Pueblos Indígenas y Afrodescendientes en América Latina", en la Universidad Nacional de Tres de Febrero (UNTREF). Argentina. E-mail: alvaroguaymas@yahoo.com.ar. ORCID: https://orcid.org/0000-0002-6012-748X.
}

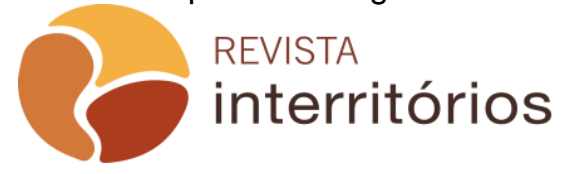


causa a pura abstração e a opõem ao pensamento enraizado na profunda Abya Yala (América para os ocidentais), sem reivindicações de universalidade para entender o que acontece nas escolas de lugares inóspitos no noroeste da Argentina, na fronteira com o Chile e a Bolívia, aprendeu com projetos de pesquisa, nos quais participaram membros de comunidades e escolas, com a intenção de analisar problemas e sustentar práticas pedagógicas interculturais.

Tempo/Espaço. Cultura Andina. Escola. Pedagogia Intercultural. Salta.

\section{School space-time categories and Andean: a study of the Northeast Argentina Schools}

\section{ABSTRACT}

The article approaches the time/space categories, in their structuring dimension, to try their denaturation, that is, think about them and accept that they are historical-cultural constructions. Therefore, a comparison between the categories of western modernity and those of Andean culture is suggested, following the guidelines of diatopic hermeneutics, as Josef Esterman's statement. In addition, the contributions of the decolonial turn that call into question pure abstraction and oppose it to the thought rooted in the deep Abya Yala (America for the Westerners) are taken, without pretensions of universality to understand what happens in schools in inhospitable places of northwestern Argentina, on the border with Chile and Bolivia, based on lessons learned through research projects, in which members of communities and schools participated, with the intention of analyzing problems and underpin intercultural pedagogical practices.

Time/Space. Andean culture. School. Intercultural Pedagogy. Salta.

\section{Categorie spazio-temporale scolastiche e andine: uno studio nelle scuole del nord-ovest dell'Argentina}

\section{RIASSUNTO}

L'articolo tratta le categorie di tempo/spazio, nella loro dimensione strutturante, per tentare la loro denaturazione, cioè per pensarci e accettare che sono costruzioni storico-culturali. Pertanto, si suggerisce un confronto tra le categorie della modernità occidentale e quelle della cultura andina, seguendo le linee guida dell'ermeneutica diatopica, come afferma Josef Esterman. Inoltre, vengono presi i contributi del decoloniale che mettono in discussione la pura astrazione e si oppongono al pensiero radicato nel profondo Abya Yala (America per gli occidentali), senza pretese di universalità per capire cosa succede nelle scuole di luoghi inospitali nel nord-ovest. de Argentina, al confine con Cile e Bolivia, ha appreso da progetti di ricerca a cui hanno partecipato membri di comunità e scuole, con l'intenzione di analizzare i problemi e sostenere pratiche pedagogiche interculturali. 
Tempo/Spazio. Cultura Andina. Scuola. Pedagogia Interculturale. Salta.

\section{Pensar sobre el pensamiento}

El desafío de pensar sobre nuestro pensamiento nos acerca a ser conscientes de nuestro sentido común, como una dimensión de la cultura asociada a la idea de orden que encontramos en lo familiar, y sobre el cual podemos actuar con eficiencia. El sentido común configura los límites de nuestro conocimiento y nos confiere tranquilidad interna. Geertz (1998, p. 115) dice que para acceder al sentido común tenemos que tomar desvíos, pues "se halla tan ingenuamente ante nuestros ojos que nos resulta casi imposible verlo".

Pensamos que nuestro sentido común está habitado por las categorías modernas instituidas desde el lenguaje y la escolaridad, por lo que proponemos estas reflexiones como una ocasión para cuestionar la trasmisión del legado eurocéntrico con el cual corremos el riesgo de repetir la opresión.

A modo de ejercicio, tomaremos las categorías de tiempo/espacio, en su dimensión estructurante, para intentar su desnaturalización, es decir para pensar sobre ellas y aceptar que son construcciones histórico-culturales. Siguiendo a Elías, las consideramos como productos históricamente variables con una función de coordinación de la actividad humana. Sin embargo, en el sentido común estas nociones son espontáneamente sustancializadas remitiendo a una realidad que parece existir fuera de los seres humanos e independientemente de ellos. Así se forma una nueva noción del tiempo como una constante cuantificable e indefinidamente reproducible de "las leyes de la naturaleza" (HEINICH, 1999, p. 47). Tiempo y espacio son interdependientes y ambos establecen relaciones posicionales: el tiempo al interior de un continuo evolutivo y el espacio entre acontecimientos móviles.

Apoyando la idea de producción humana variable en las diferentes culturas, este texto insinúa una comparación entre las categorías de la modernidad occidental con los de la cultura andina, siguiendo los lineamientos de la hermenéutica diatópica tal como la enuncia Josef Esterman (2016). De acuerdo a este autor, el pensamiento andino corresponde a un tipo de racionalidad propio que se distingue en muchos aspectos del tipo de racionalidad dominante de Occidente. Desde esta evidencia, hablar de una "racionalidad múltiple" permite hablar de una variedad cultural y civilizatoria de racionalidades.

Una hermenéutica diatópica es, al mismo tiempo, una hermenéutica intercultural de distintas racionalidades que están enraizadas en coordenadas espacio-temporales. Por lo contrario, nosotros y otros, como nosotros fuimos entrenados para pensar sin tener en cuenta

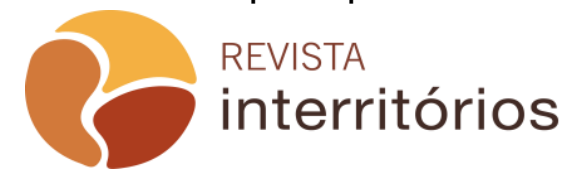

Interritórios | Revista de Educação

Universidade Federal de Pernambuco, Caruaru, BRASIL | V.5 N.9 [2019] 
las condiciones donde ese pensamiento se elaboraba, se realizaba y reconocía como verdad y poder.

Pero, desde la opción decolonial, nuestro pensamiento intentará acompañar nuestros pasos y los de quienes transitan por territorios eliminados del poder pensar académico, pues tal como decía Pablo Freire "La cabeza piensa donde los pies pisan" (FREI BETO, s/f).

El giro decolonial duda de la abstracción pura y la contrapone al pensamiento enraizado en la Abya Yala profunda (América para los occidentales), sin pretensiones de universalidad. Este pensamiento viene a contagiar formas, sonidos, sabores, olores y colores que dicen sobre rostros, manos, nombres, historias, resistencias, dolores, triunfos, cansancios, derrotas y desapariciones...

En el espacio acotado de esta escritura, limitaremos este amplio planteo a lo que sucede en las escuelas de lugares inhóspitos del noroeste de Argentina, en la frontera con Chile y Bolivia.

\section{En zona andina}

En un entorno montañoso y árido, existen pequeños poblados dispersos, que conservan un rico patrimonio arqueológico y cultural, aunque erosionado por una historia de explotación y expropiación. Así es cómo los lugareños de esta zona perdieron sus lenguas originarias, de las cuales se conservan solo algunos vocablos y topónimos. En esa extensa geografía, las familias de campesinos, pastores, mineros, viven dispersas y aisladas, manteniendo sus tradiciones milenarias y produciendo para la subsistencia. Estas adversas condiciones de vida impidieron la alfabetización de los mayores y dificultan todavía hoy las de niñas, niños y jóvenes.

En aquellos lugares donde se agrupaban varias familias, el Estado abrió pequeñas escuelas, que funcionan con dos o tres docentes y con grados agrupados o plurigrados; también se crearon escuelas unitarias, donde concurren estudiantes de todas las edades, a cargo de un solo docente. En menor número, se edificaron y abrieron centros educativos con albergues, dotados de más servicios, donde los escolares pueden comer y dormir durante la semana, sin tener que recorrer diariamente, las grandes distancias que los separan de sus hogares. Más recientemente, al extenderse los años de obligatoriedad escolar, se creó un sistema de itinerancia con docentes para disciplinas especiales a fin de reforzar los aprendizajes; con esa misma modalidad de itinerancia se han creado algunos instituciones educativas para el Nivel de Educación Medie o más conocida con el nombre de Escuela Secundaria. 
Desde el Centro de Investigaciones Sociales y Educativas del Norte argentino (Cisen) años atrás, a pedido de algunas de las escuelas y/o de las comunidades, participamos en proyectos de extensión y voluntariado universitarios, con apoyo de otros Institutos de la Universidad Nacional de Salta (UNSa) y organismos del Estado. Paralelamente, desarrollamos proyectos de investigación, en los cuales participaron miembros de las comunidades y de las escuelas, con la intención de analizar problemas y apuntalar las prácticas pedagógicas interculturales.

Durante el recorrido teórico y empírico de este trabajo reconstruimos muchas "escuelas" o momentos diferentes en la educación de la zona, donde detectamos tanto la presencia/ausencia de políticas públicas como el accionar positivo/negativo de las personas o grupos responsables. En resumen, intentando una periodización, podemos distinguir las siguientes etapas:

1. Los borrosos orígenes, donde los primeros maestros que llegan son recordados como buenos, "enseñaban más", vivían y participaban en la comunidad; quizás, y en términos relativos, representaron la introducción tenaz de la "civilización occidental y moderna" (principios del siglo XX).

2. El tiempo donde "no llegaban maestros", y si aparecía alguno estaba un tiempo y se iba, dejando otra vez cerrada la escuela. En otros parajes "no se conocía escuela". Coincide con las décadas en que las familias se trasladaban a las plantaciones de cañas de azúcar en la región amazónica del noroeste argentino (hasta más allá de mediados del siglo XX).

3. Entre los años setenta y el fin de siglo $X X$, con maestros "... buenos, pero que no enseñan tanto", preocupados por mantener el comedor y muchas otras tareas que los alejan de la enseñanza; los docentes viven lejos, van y vienen, traen innovaciones pero no permanecen. En los últimos años de la década del noventa, se mejoran los edificios escolares y los directores disponen de fondos para comprar materiales didácticos.

4. En la década de 1990, desde la reforma de la Educación General Básica y el aumento de los años de obligatoriedad, algunas características de las prácticas escolares son:

$\checkmark$ incorporación de docentes especializados itinerantes: profesora de nivel inicial, algunos profesores de disciplinas 0 especializados, por ejemplo, inglés, ciencias biológicas, agronomía, etc.

$\checkmark$ mejoras en infraestructura edilicia y algunos servicios, como agua corriente y luz eléctrica, a través de paneles solares 0 generadores;

$\checkmark$ disponibilidad de recursos didácticos electrónicos: TV, video reproductor, grabador, amplificador, filmadora, cámaras fotográficas; en algunos casos radiotransmisores o hasta radio FM de potencia limitada con fines educativos;

$\checkmark$ biblioteca: libros para los docentes y para los estudiantes.

5. El siglo XXI con internet y la telefonía celular ha mejorado algunos aspectos de la 
educación en los pocos sitios donde esta tecnología ha logrado llegar.

Cabe aclarar que cambios y mejoras no alcanzan a todos los establecimientos educativos; por otra parte, se van cerrando secciones y escuelas como resultado de un doble proceso: la emigración de los nativos y las medidas de "reducción del gasto público", que justifican un cargo docente por 18 estudiantes.

También las prácticas pedagógicas-didácticas en dichos contextos adquirirán significaciones contrapuestas, hasta tensar la relación entre un deber ser ineludible y una realidad irreductible (SAHLINS, 1985); ineludible en tanto los conceptos proceden del sistema cultural admitido y dominante. Por otra parte son irreductibles, en tanto configuran una acción única, singular, en el presente del mundo.

Argumentamos sobre lo arbitrario e injusto de aquello que aparece como obvio, es decir sobre cómo se organiza el calendario, el currículo y las prácticas escolares cotidianas. Objetivamente, al planificar y pautar la distribución de conocimientos sobre un tiempo lineal, dividido en intervalos secuenciados, la escuela coloca en desventaja a quienes no comparten esta experiencia del tiempo y de la vida.

Para entender las interrelaciones entre las comunidades y sus escuelas, tendremos que intersectar los vínculos entre sus agentes, ya que quienes entran en contacto son personas. Por lo tanto, una de las claves es cada docente, otra cada estudiante, quienes están emparentados entre sí y con la persona que se ocupa de la limpieza y el mantenimiento del edificio escolar o con la cocinera. Y por supuesto, el padre o la abuela, el tío o la hermana mayor, en fin, el encargado de asegurar la subsistencia, pero también quienes arreglan techos y puertas. Pero hay otros agentes que, aunque ausentes, son responsables de la administración de estas instituciones y de cómo responden a las necesidades con la comunidad.

Agentes responsables pero ausentes son funcionarios y autoridades, los que simplemente con designaciones y seguimientos pertinentes podrían contribuir a mejorar la situación de los docentes y las escuelas. Para lo cual, será imprescindible conocer las particularidades de la zona inhóspita y valorar la experiencia de equipos docentes e instituciones responsables. Al mismo tiempo, apoyar a quienes ensayan innovaciones apropiadas, sobre todo las orientadas a mejorar las condiciones de vida de las familias andinas.

A partir de reuniones en las que asistieron docentes, directivos y supervisores de zona, implementamos actualizaciones sobre temas de su interés y finalmente, una carrera de Especialización en Educación Rural e Intercultural, de dos años y medio de duración, para educadores en servicio en esta región. Esta carrera puso en marcha un 
dispositivo de acompañamiento "in situ" de los docentes participantes, con las siguientes ventajas:

$\checkmark$ Permitió visualizar la relación práctica-teoría-práctica.

$\checkmark$ Posibilitó poner en práctica las propuestas alternativas elaboradas en el trabajo grupal.

$\checkmark$ Facilitó el diálogo en las instituciones educativas, con padres y referentes de las organizaciones indígenas y campesinas.

$\checkmark$ Abrió el diálogo intercultural permitiendo a un número significado de docentes volver a pensar sobre sus prejuicios y el racismo naturalizado en el día a día en la escuela en particular, y en la sociedad salteña en general.

Al mismo tiempo que trabajamos en formación con docentes de la zona andina, continuamos acompañando y aprendiendo con los pobladores, en algunos casos con mujeres, como en la localidad de El Barrial (Municipio de San Carlos), o con las campesinas del Consejo de Pueblos de Tastil (CPT) en la Quebrada del Toro, y también en la Pre Cordillera Salta-Jujeña con la Organización Indígena Coya de Nazareno (OCAN). También participamos en algunas instancias de capacitación del Programa Nacional de Educación Intercultural, que nos puso en contacto con educadores de un territorio más amplio del noroeste argentino.

En la soledad de los cerros y de la puna, docentes y estudiantes hacen patente la fragilidad de lo pedagógico intercultural, luchando contra condiciones adversas. Para que emerja lo pedagógico hay que superar muchos obstáculos objetivos y subjetivos, hay que abrir la mirada y la escucha, y principalmente prestar una especial atención a las experiencias formativas.

En definitiva, consideramos que a lo largo de la historia de luchas por derechos y reconocimientos de los pueblos indígenas andinos, las instituciones educativas de todos los niveles se han mantenido distantes, enroladas en pos de un ideario nacional homogeneizante, que transmitía como única cultura universal, la occidental eurocéntrica.

\section{Escolaridad y categorías temporo-espaciales}

En trabajos anteriores hemos destacado las diferencias entre los modos que los pueblos indígenas andinos tienen de entender el tiempo y el espacio y las lógicas temporo-espaciales que introduce la escuela (DE ANQUIN, 2007, p. 108). En los lugares andinos hay una densa imbricación del tiempo y del espacio, donde la transmisión de saberes no requiere ningún discurso, simplemente ocurre en la práctica cotidiana.

Pero en contextos rurales e interculturales se repiten tanto el calendario,

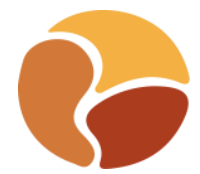


como el horario y los ritmos de enseñanza y de aprendizaje producidos y pautados en y para la ciudad que representa la modernidad occidental disciplinadora. La organización escolar forma parte de un sistema simbólico acorde con la división del trabajo en una sociedad capitalista, sin necesidad de que sus portadores (docentes y estudiantes) sean conscientes de ello. Prácticas escolares como la inmovilidad silenciosa del aula, el recreo en el patio o el conocimiento dividido en asignaturas, portan creencias y jerarquías sociales. Para Bernstein (1996), el poder dominante se transmite y controla a través de las formas de organizar el tiempo y el espacio escolar y áulico, dividiendo y aislando sus componentes.

Al respecto, explica Mendoza (2000, p. 203) que el uso de la organización temporo-espacial oficial

pone de relieve la autoridad, el prestigio y jerarquía de quien instituye y delimita el campo de lo educativo, imponer estas prácticas de serialización y fragmentación del tiempo y el espacio, da cuenta del desinterés histórico que tiene la escuela por la forma en cómo las comunidades donde se inserta, organizan estas categorías.

Como explica Estermann (2017, p. 10), en la concepción andina del tiempo el pasado está adelante y el futuro atrás, al revés que en las categorías modernas:

\footnotetext{
Pero en última instancia, lo de arriba y lo de abajo, lo de atrás y lo de adelante, se concentran en el aquí y ahora, y todas estas dimensiones son expresadas por pacha. Finalmente, pacha significa en un sentido más religioso y cosmogónico el "universo ordenado". Resumiendo, se puede determinar pacha como "totalidad temporal-espacial" que se constituye "dinámicamente", debido a los polos complementarios (paridad; dualidad) y que se regenera en secuencias cíclicas (pachakuti) entre equilibrio y desequilibrio cósmicos.
}

En la escuela, la regulación del tiempo y del espacio fue pensada de otra manera, y como si fuera la única forma posible de organización, configuró un espacio y un tiempo divididos, entre si y dentro de cada categoría. Como señala Bernstein (1996) la clasificación fuerte de la escolaridad, trasmite un código jerárquico e incuestionable. En cambio, la filosofía andina tiende a la relacionalidad, como sostiene Estermann (2017, p. 12) hay una totalidad temporal-espacial equiparable al término pacha con secuencias cíclicas (pachakuti).

Otro aporte lo ofrece Julia Varela, quien retomando a Elías y a Foucault, establece las formas de individuación que impuso la modernidad, justamente a través de la educación. La autora clarifica las relaciones construidas 
históricamente entre las tecnologías de producción de subjetividades específicas y las reglas que rigen la constitución de los campos del saber (VARELA en LARROSA, 1995, p. 155-189).

La historiadora española invoca a Michel Foucault (citado en VARELA, 1995 , p. 163) cuando este filósofo francés demuestra que el tiempo y el espacio se reorganizaron en el siglo XVII a través del ejercicio de un nuevo tipo de poder que denominó disciplinario. El poder disciplinario parte del principio de que es más rentable vigilar que castigar: domesticar y hacer productivos a los sujetos es más rentable que segregarlos o eliminarlos, lo que ocurrió (y ocurre) en instituciones educativas, tales como las escuelas y los secundarios rurales del noroeste de Argentina.

En el artículo citado, Varela afirma que

Las pedagogías disciplinarias no pueden ser analizadas, por tanto, a partir de la noción de represión ya que sus efectos, como estamos viendo, son enormemente productivos: suponen un cambio en la percepción social del espacio y del tiempo, cambio que se manifiesta a la vez en la organización del espacio y el tiempo pedagógicos y en su interiorización por los colegiales. Estas pedagogías son asimismo un instrumento de primer orden en la construcción, por una parte, de una forma de subjetividad nueva, el individuo, y, por otra, en la organización del campo del saber. (VARELA, 1995, p. 166167).

Finalmente, la autora de cuyo discurso nos hemos apropiado, expresa: "La transmisión de categorías de pensamiento en la escuela y su interiorización son hoy fundamentales para el mantenimiento del statu quo, del orden escolar y del orden social." (VARELA, 1995, p, 188).

\section{Algunas relaciones que abren más posibilidades de reflexión}

Comprender los procesos de colonialidad del poder (QUIJANO, 2000) y sus efectos en nosotros despierta resonancias poderosas particulares, porque somos gentes del "interior" de Argentina y participamos de identidades indígenas y mestizas. El pensamiento colonial mantiene un eco persistente en nuestras cabezas tal que pone en riesgo nuestra identidad e insiste en lo que Walter Mignolo (2010, s/n) llama "violencia epistémica":

el vuelco epistémico decolonial gira hacia una universalidadotra, hacia la pluriversalidad como proyecto universal. En sus interesantes reflexiones enuncia una corpopolítica del conocimiento como respuesta a la biopolítica, con la cual Europa intentó el dominio del mundo colonial. Para este 
pensador argentino, la corpopolítica es una epistemología que se desprende del "pienso, luego existo" y afirma que "se es donde uno piensa."

Por cierto, no vivimos con facilidad este complejo atravesamiento que impacta en la identidad personal y que se hace visible en nuestras prácticas. A nuestro pesar debemos reconocer que hemos sido formados en el pensamiento único eurocéntrico y que trabajamos en su desalojo para que fructifique un pensamiento otro, que cuestione la colonialidad del poder y la racialización.

En cambio, el pensamiento andino es en un primer momento noconceptual (lo que aparece para la perspectiva occidental una contradicción en sí misma), lo que no es lo mismo como "pre-conceptual" o "pre-lógico". Se trata de un pensamiento relacional que tiene una orientación holística, donde los elementos que corresponden "homeomórficamente" a conceptos occidentales, tienen significado simbólico y representativo, pero que siempre están insertados en un conjunto concreto de fenómenos vitales.

Como ya dijimos, pacha no es el resultado de un proceso de abstracción relativamente complicado, sino el punto de partida en el mundo vivencial para muchos campos de aplicación. Asumir este pensamiento andino, implica un trabajo de orientación de-colonial dirigido a quitar las cadenas que aún están en las mentes, como decía el intelectual afrocolombiano Manuel Zapata Olivella, desesclavizar las mentes como decía Malcolm X, y desaprender lo aprendido para volver a aprender, como argumenta el abuelo del movimiento afroecuatoriano Juan García.

Catherine Walsh $(2014, \mathrm{~s} / \mathrm{n}$ ) ilustra nuestro planteo decolonial, en el sentido de revisar categorías de pensamiento y sentido común, ya que se trata de

un trabajo que procura a desafiar y derribar las estructuras sociales, políticas y epistémicas de la Colonialidad -estructuras hasta ahora permanentes- que mantienen patrones de poder enraizados en la racialización, en el conocimiento eurocéntrico y en la inferiorización de algunos seres como menos humanos.

En síntesis, generar discusión, reflexión y crítica al pensamiento hegemónico rompe con un orden instituido que domina, quizás hasta y desde acotando el tiempo cada vez más exiguo del que disponemos. Pero cuando estas acciones son valoradas y reconocidas en lo que ellas potencian y representan: posibilidad de hacernos más conscientes de las categorías de pensamiento que nos habitan -aún a pesar nuestro- y co-construir subjetividad individual y colectiva, todo esfuerzo adquiere sentido. 


\section{REFERÊNCIAS}

BERNSTEIN, B. Pedagogía, control simbólico e identidad. Madrid: Paideida Morata. 1996.

DE ANQUÍN, A. Zona Inhóspita. De maestros y pobladores, de lugares y tiempos. Salta: EUNSa. 2007.

ESTERMANN, J. Hermenéutica diatópica y filosofía andina. Esbozo de una metodología del filosofar intercultural. FAIA, v. 6, n. 27, p. 1-17. 2017.

FREI BETO (s/f). Paulo Freire: una lectura del mundo. Recuperado el 2 de noviembre de 2018, de https://www.nodo50.org/americalibre/anteriores/13/freire13.htm.

GEERTZ, C. Conocimiento local. Barcelona: Paidós. 1983.

HEINICH, N. Norbert Elías. Historia y cultura en Occidente. Buenos Aires: Nueva Visión. 1999.

MENDOZA, M. La escuela y la subjetividad de los collas. Anuario de la Facultad de Ciencias Humanas de la Universidad Nacional de La Pampa, 5, 197-208. 2000.

MIGNOLO, W. Desobediencia epistémica. Buenos Aires: Signo. 2010.

QUIJANO, A. Colonialidad del poder, eurocentrismo y América Latina. En E. Lander (Comp.), La colonialidad del saber: eurocentrismo y ciencias sociales.

Perspectivas Latinoamericanas (p. 201-246). Buenos Aires: 2000.

SAHLINS, M. Islas de historia. La muerte del capitán Cook, metáfora, antropología e historia. Barcelona: Gedisa. 1985.

VARELA, J. Categorías espacio-temporales y socialización escolar: del individualismo al narcisismo. En J. Larrosa (ed.), Escuela, Poder y subjetivación. Madrid: La Piqueta, 1995.

WALSH, C. Interculturalidad crítica y pedagogía de-colonial: apuestas (des)de el insurgir, re-existir y re-vivir. Recuperado el 29 de octubre de 2018, de https://www.scoop.it/t/comunicacion-y-cultura-by-pedro-nelburgos/p/4014060336/2014/01/12/interculturalidad-critica-y-pedagogia-de-colonialapuestas-des-de-el-in-surgir-re-existir-y-re-vivir-catherine-walsh. 